\title{
Sitios prioritarios para la recuperación de bosque nativo intervenido en la Región de Los Ríos, Chile.*
}

\author{
Proposal for priority areas for intervened native forests recovery in Los Ríos Region, Chile.
}

\author{
Carolina A. Lizana ${ }^{\mathrm{a}}$ y Alvaro G. Gutiérrez
}

Historial del artículo

Recibido:

28 de agosto del 2018

Aceptado:

15 de marzo del 2019. a Departamento de Ciencias Ambientales y Recursos Naturales Renovables, Facultad de Ciencias Agronómicas, Universidad de Chile, Santiago, Chile. Correo electrónico: carolinalizana1@gmail.com

*Este trabajo se realizó con el apoyo del Fondo de Investigación del Bosque Nativo de CONAF 027/2015

\section{Palabras clave}

Bosque Templado Lluvioso Valdiviano, Evaluación Multicriterio, Priorización Ecológica

\section{Keywords}

Ecological Prioritization, Multicriteria Evaluation, Valdivian Temperate Rain Forest

\begin{abstract}
Resumen
El bosque templado lluvioso valdiviano es considerado una de las ecorregiones más relevantes a nivel mundial debido a su importancia biológica. Sin embargo, sus bosques han sido constantemente sometidos a intervenciones antropogénicas, afectando su funcionalidad, composición y estructura, llevándolo a ser altamente prioritario de recuperar. Debido a lo anterior, se determinaron zonas prioritarias para la recuperación de bosque nativo intervenido del bosque templado lluvioso valdiviano en la Región de Los Ríos. En primera instancia, se realizó una revisión de criterios ecológicos discutidos en la literatura, los cuales fueron seleccionados según su aplicabilidad al área de estudio y a la disponibilidad de coberturas para su espacialización. Posteriormente, tales criterios se valoraron y jerarquizaron mediante la aplicación de cuestionarios a diferentes expertos en ecología y conservación de bosques nativos. Luego, esta información fue integrada a un modelo de evaluación multicriterio a partir de sistemas de información geográfica, permitiendo generar un mapa de sitios prioritarios. De acuerdo con los juicios de expertos, los principales criterios son: riqueza de especies en categoría de conservación y el tamaño de la unidad de análisis. Se identificaron 31 sitios prioritarios, abarcando una superficie total de 6.582 hectáreas, concentrados en la comuna de Panguipulli. Finalmente, los sitios identificados proporcionan una primera aproximación para dirigir y evaluar acciones de recuperación. Sin embargo, para que estas acciones sean efectivas, se recomienda incorporar otras dimensiones, buscando soluciones locales, considerando una estrategia de financiamiento y la dinámica natural del bosque.
\end{abstract}

\section{Abstract}

The Valdivian Temperate Rainforest ecoregion is considered as one of the most relevant ecoregions in the world due to its biological importance. However, the native forests of this ecoregion have been historically subjected to anthropogenic disturbances, affecting its functionality, composition and structure and making it a high priority to recover. Because of this, it is necessary to determine which are the priority zones for the recovery of intervened forest in the Valdivian Rainforest to guide the organizations responsible for the management and protection of native forests. This study identified the priority areas for the recovery of intervened native forest in Los Ríos Region, Chile. In a first instance, an exhaustive review of ecological criteria commonly discussed in the literature was carry out, which were selected according to their applicability to the study field and the availability of coverages for its spatialization. Subsequently, those criteria were rated and hierarchized by the application of questionnaires to different experts in ecology and forest conservation of Los Rios Region. This information was integrated into a multicriteria evaluation model from SIG, to generate a map of priority sites. The main ecological criteria are the species richness in conservation category, the size of the unit of analysis and the richness of key species. The relative weights of each criterion in the multi-criteria evaluation 31 priority sites were identified, covering a total area of 6,582 hectares, with the highest number of analysis units in Panguipulli. The identified sites provide a first approximation to guide and evaluate future recovery actions. However, for these actions to be effective it is recommended to incorporate other dimensions, such as social, economic and institutional, seeking local solutions for each priority area, considering a financing strategy and the natural dynamics of the forest to recover. 


\section{Introducción}

La degradación forestal es un proceso antrópico que genera la pérdida de productividad, biodiversidad y estructura de los bosques (Ghazoul, Burivalova, García-Ulloa, \& King, 2015). Para transformar y mejorar paulatinamente la estructura y funciones ecosistémicas de bosques intervenidos, la recuperación ecológica aparece como práctica orientadora de actividades de manejo (Organización Internacional de las Maderas Tropicales [OIMT], 2002). Sin embargo, el alto costo asociado a la recuperación de bosques intervenidos hace que sea necesario priorizar dónde es urgente ejercer medidas de protección en el contexto territorial en que se insertan los bosques bajo estudio (Fernández, Morales, Olivares, Salvatierra, Gómez \& Montenegro, 2010). Dentro de este aspecto, los bosques intervenidos con alto valor de conservación son considerados como prioridades para las actividades que apunten a su recuperación (Bannister et al., 2013).

Chile posee una alta variedad de hábitats y formaciones vegetales, las que conforman doce ecorregiones distribuidas a lo largo del territorio nacional (Ministerio del Medio Ambiente [MMA], 2011; Gajardo, 1994). Dos de estas ecorregiones son consideradas relevantes a escala global por su importancia biológica: la Ecorregión de Matorral de Chile Central y la Ecorregión del Bosque Templado Lluvioso Valdiviano (Myers, Mittermeier, Mittermeier, da Fonseca \& Kent, 2000). Esta última representa una de las cinco ecorregiones de bosques templados lluviosos en el mundo y la única en América del Sur (WWF 2004; Olson \& Dinerstein, 2002). Sin embargo, los bosques han sido históricamente sometidos a extracción maderera, a deforestación producida por el avance de la frontera agrícola, ganadera y forestal, y a la habilitación de vías de transporte (Camus, 2008), a lo que se agrega la introducción de especies exóticas, que compiten directamente con especies nativas y modifican procesos ecológicos (Quiroz, Pauchard, Marticorena \& Cavieres, 2009). Tales procesos de degradación conllevan a que su estado actual de conservación sea vulnerable con máxima prioridad (Echeverría, Newton, Lara, Benayas, Coomes, 2007; MMA, 2011; Vergara \& Gayoso, 2004).

La Región de Los Ríos es una de las regiones administrativas de Chile con mayor superficie de Bosque Templado Lluvioso Valdiviano (BTLV), presentando un 49,5\% de la cobertura de bosque nativo de esta Ecorregión (Corporación Nacional Forestal [CONAF], 2014). Por lo tanto, considerando la superficie de bosque nativo primario remanente y sus características ecológicas, es necesario generar mecanismos de detección y acción temprana para detener la degradación de sus bosques nativos (Rojas, Loguercio, Nieto, \& Bahamondez, 2011). Es por ello que la Región de Los Ríos representa una oportunidad para establecer áreas de recuperación de bosque nativo intervenido.

De acuerdo con los antecedentes expuestos anteriormente, con este estudio se espera distinguir áreas prioritarias para la recuperación de bosque nativo intervenido en la Región de Los Ríos, utilizando la metodología de evaluación multicriterio y criterio experto, en base a información territorial pública. En esta investigación descriptiva, se expone una metodología de bajo costo y participativa que permite identificar los sitios prioritarios para establecer medidas de recuperación de los bosques intervenidos en la Región. La metodología puede ser replicada en otras regiones del país y se presenta como una guía para la toma de decisiones a nivel regional. Según lo anterior, el objetivo general de esta investigación es determinar zonas prioritarias para la recuperación de bosque nativo intervenido en la Región de Los Ríos, Chile, mediante la definición de criterios para distinguir el valor ecológico del bosque nativo intervenido (1), identificando aquellos criterios prioritarios para la recuperación de bosque nativo intervenido (2), y determinando un índice de priorización ecológica del bosque nativo intervenido de la Región de Los Ríos (3).

\section{Materiales y métodos}

El área de estudio corresponde al Bosque Templado Lluvioso Valdiviano de la Región de Los Ríos, cuya distribución se determinó mediante las coberturas de bosque nativo identificadas por el Catastro y Evaluación de los Recursos Vegetacionales Nativos de la Región de Los Ríos (CONAF, 2014). En la Región de Los Ríos habitan al menos 1.023 especies de plantas vasculares nativas pertenecientes al Bosque Templado Lluvioso Valdiviano (Comisión Nacional del Medio Ambiente [CONAMA], 2010). Además, se encuentran representados ocho tipos forestales: Alerce, Ciprés de las Guaitecas, Araucaria, Ciprés de la Cordillera, Roble-Raulí-Coigue, CoigueRaulí-Tepa, Lenga y Siempreverde (CONAF, 2014). En particular, el $28 \%$ de especies de plantas vasculares y el $29,3 \%$ de plantas no vasculares de la ecorregión son endémicas de Chile y Argentina, agregándose a esto un elevado número de géneros monotípicos (Aizen \& Ezcurra, 1998).

El Bosque Templado Lluvioso Valdiviano en la Región de Los Ríos ha sido sometido a diferentes disturbios naturales y antrópicos. Dentro de este aspecto, los primeros corresponden a eventos naturales discretos en el tiempo, 
cuya acción puede dañar parcial o totalmente un ecosistema forestal (Baldini \& Pancel, 2000). Los disturbios naturales que ocurren a escalas espaciales mayores son comúnmente el vulcanismo y los movimientos sísmicos, los cuales originan deslizamientos de tierra, inundaciones y coladas de lava. Ambos tipos de disturbios afectan la estructura, composición, distribución y variabilidad de los bosques nativos (Baldini \& Pancel, 2000; Tacón, 2004; Armesto, Villagrán \& Arroyo, 1996). En tanto, la intervención hacia el Bosque Templado Lluvioso Valdiviano en la Región de Los Ríos incluye el desarrollo de actividades agro-ganadera y forestal, las que han provocado una fuerte transformación del bosque, llevándolo a presentar distintos niveles de degradación (Armesto \& Ramírez, 1994; Vergara \& Gayoso, 2004).

La metodología de análisis espacial aplicada este estudio incluyó cuatro pasos metodológicos: (1) se delimitó del área de estudio en Unidades de Análisis. Posteriormente, (2) se identificaron criterios ecológicos que permitieron inferir el estado actual de intervención de un bosque mediante revisión bibliográfica. Luego, (3) se integraron estos criterios utilizando Sistemas de Información Geográficos (GIS) en una matriz de Evaluación Multicriterio, y (4) se valoraron los criterios según Juicio Experto.

Como se expuso previamente, se reconoció en específico el área de estudio mediante la definición de Unidades de Análisis (UA), las que corresponden a rodales de bosque nativo adulto intervenido en la Región de Los Ríos. Para la construcción de las Unidades de Análisis, se unieron las coberturas del Catastro de Bosque Nativo (CONAF, 2014) y del Inventario Forestal (Instituto Forestal [INFOR], 2010) mediante el uso de software GIS y sus herramientas de geoprocesamiento. De acuerdo con la información del Catastro de Bosque Nativo (CONAF, 2014) se identificaron rodales de bosque nativo adulto en la Región de Los Ríos y se seleccionaron aquellas estructuras únicas de bosque nativo adulto, homogeneizándose sus niveles de densidad (abierto, denso o semi-denso), resultando tres clasificaciones: Bosque adulto, Bosque adulto/renoval y Bosque achaparrado. Posteriormente esta información se entrelazó con el grado de intervención antrópica propuesto en el protocolo de muestreo del Inventario Forestal continuo del Instituto Forestal (INFOR, 2010). Según este inventario, el grado de intervención antrópica para cada muestra se refiere a efectos visibles de la intervención del hombre sobre el recurso forestal, tales como: manejo, incendios, pastoreo, producción de carbón, etc.

Posteriormente, para identificar los criterios ecológicos se realizó una revisión bibliográfica de los criterios ecológicos utilizando fuentes de datos generados por autores en estudios de Evaluación Multicriterio previos (Branquart, Verheyen \& Latham, 2008; Orsi \& Geneletti 2010; Orsi, Geneletti \& Newton, 2011; Phua \& Minowa, 2005). Cabe señalar que la metodología de Evaluación Multicriterio ha sido ampliamente utilizada en estudios similares ya que integra un conjunto de técnicas que se orientan a asistir el proceso de la toma de decisión (Gómez Delgado \& Barredo Cano, 2005, Saaty, 2008).

Se consideró como criterio ecológico a cualquier variable, atributo o componente de un bosque y su entorno, que puede ser utilizado para inferir el estado actual de intervención antrópica del bosque (Navarro et al. 2008), y que permite la priorización ecológica de las unidades espaciales del paisaje. Considerando la definición anterior, se establecieron criterios ecológicos mediante la revisión de literatura científico-técnica sobre criterios ecológicos que han sido comúnmente utilizados para establecer áreas prioritarias para la conservación, preservación y/o recuperación de bosque nativo, además de zonificaciones o valoraciones ecológicas. Luego, para cada criterio ecológico seleccionado se definió una variable espacial representativa, la cual permitió definir los insumos cartográficos que se usan para su construcción y los procesos de análisis espacial en las coberturas utilizadas (tabla 1). Las variables fueron capas vectoriales, las cuales fueron geo-referenciadas a WGS84 UTM 19S y geo-procesadas con software GIS, específicamente se usaron herramientas de proximidad, generalización, intersección, área de influencia y superposición.

En cuanto al procedimiento de asignación de valor de los criterios ecológicos, se utilizó la aplicación de cuestionarios a expertos (Hernández, Fernández \& Baptista, 2010). El tipo de muestreo fue no probabilístico con muestra incidental (Argibay, 2009), específicamente de juicio o propósito (Hernández et al., 2010). La muestra fue de expertos relacionados con las ciencias ambientales y ecológicas con énfasis en bosque nativo de la Región de Los Ríos, incluyendo instituciones académicas (Universidad Austral de Chile, Instituto de Ecología y Biodiversidad, Instituto Forestal, Universidad de Chile y Universidad de La Frontera), privadas (Aprobosque AG), gubernamentales (Corporación Nacional Forestal Los Ríos y Secretaria Regional Ministerial Ministerio de Medio Ambiente Los Ríos) y organizaciones no gubernamentales (WWF-Chile, The Nature Conservancy).

La recolección de datos se realizó a partir de cuestionarios aplicados a expertos, donde se solicitó responder las siguientes preguntas: 
Tabla 1

Criterios ecológicos seleccionados de acuerdo a la revisión de la literatura científico-técnica.

\begin{tabular}{|c|c|c|c|}
\hline Criterios ecológicos & Variable & Información cartográfica & Metodología GIS \\
\hline $\begin{array}{l}\text { Cercanía de la unidad de } \\
\text { análisis con el área protegida } \\
\text { más cercana. }\end{array}$ & $\begin{array}{l}\text { Distancia entre la unidad de } \\
\text { análisis al área protegida } \\
\text { más cercana. }\end{array}$ & $\begin{array}{l}\text { Cobertura del Sistema Nacional de Áreas } \\
\text { Silvestres Protegidas proveniente de } \\
\text { Infraestructura de Datos Geoespaciales } \\
\text { (IDE) del Ministerio de Bienes Nacionales } \\
\text { del Gobierno de Chile. }\end{array}$ & $\begin{array}{l}\text { Análisis de proximidad entre las Unidades } \\
\text { de Análisis y las áreas silvestres protegidas. }\end{array}$ \\
\hline $\begin{array}{l}\text { Riqueza de especies en } \\
\text { categoría de conservación } \\
\text { en la unidad de análisis. }\end{array}$ & $\begin{array}{l}\text { Número de especies de } \\
\text { vegetación y flora nativa en } \\
\text { categoría de conservación } \\
\text { en la unidad de análisis. }\end{array}$ & $\begin{array}{l}\text { Puntos georreferenciados de especies en } \\
\text { categoría de conservación a partir de una } \\
\text { solicitud de Acceso a la Información Pública } \\
\text { de la Oficina de Informaciones, Reclamos y } \\
\text { Sugerencias (OIRS) del Ministerio del Medio } \\
\text { Ambiente, e información de Global Index of } \\
\text { Vegetation plot Databases (SA-CL-002 2016) }\end{array}$ & $\begin{array}{l}\text { Creación de áreas buffer de } 10 \text { metros para } \\
\text { cada dato de presencia de especies en } \\
\text { categoría de conservación. Intersección de } \\
\text { buffer con Unidades de Análisis. }\end{array}$ \\
\hline $\begin{array}{l}\text { Cercanía de la unidad de } \\
\text { análisis con otros bosques } \\
\text { nativos. }\end{array}$ & $\begin{array}{l}\text { Distancia entre la unidad de } \\
\text { análisis y el bosque nativo } \\
\text { más cercano. }\end{array}$ & $\begin{array}{l}\text { Catastro de Bosque Nativo (CONAF, 2014) } \\
\text { e Inventario forestal del Instituto Forestal } \\
\text { (INFOR, 2010) }\end{array}$ & $\begin{array}{l}\text { Análisis de proximidad entre las Unidades } \\
\text { de Análisis y los polígonos generados para } \\
\text { bosque nativo. El bosque nativo se identificó } \\
\text { mediante intersección de las capas vectoriales } \\
\text { del Catastro de Bosque Nativo y el Inventario } \\
\text { Forestal. }\end{array}$ \\
\hline $\begin{array}{l}\text { Tamaño de la unidad de } \\
\text { análisis. }\end{array}$ & $\begin{array}{l}\text { Superficie cubierta por la } \\
\text { unidad de análisis. }\end{array}$ & $\begin{array}{l}\text { Catastro de Bosque Nativo (CONAF, 2014) } \\
\text { e Inventario forestal del Instituto Forestal } \\
\text { (INFOR, 2010) }\end{array}$ & $\begin{array}{l}\text { Cálculo de área mediante herramientas } \\
\text { geométricas. }\end{array}$ \\
\hline $\begin{array}{l}\text { Estructura de la unidad de } \\
\text { análisis. }\end{array}$ & $\begin{array}{l}\text { Perfil vertical del dosel de } \\
\text { acuerdo a CONAF (2014) }\end{array}$ & Catastro de Bosque Nativo (CONAF, 2014) & $\begin{array}{l}\text { Selección de la categoría "Estructura" de la } \\
\text { capa vectorial del Catastro de Bosque Nativo. }\end{array}$ \\
\hline $\begin{array}{l}\text { Riqueza de especies nativas } \\
\text { en la unidad de análisis. }\end{array}$ & $\begin{array}{l}\text { Número de especies de } \\
\text { vegetación y flora nativa } \\
\text { presentes en la unidad de } \\
\text { análisis. }\end{array}$ & $\begin{array}{l}\text { Global Index of Vegetation plot Databases } \\
\text { (SA-CL-002 2016), Catastro de Bosque } \\
\text { Nativo (CONAF, 2014) e Inventario forestal } \\
\text { del Instituto Forestal (INFOR, 2010) }\end{array}$ & $\begin{array}{l}\text { Creación de áreas buffer de } 10 \text { metros } \\
\text { para cada dato de riqueza de especies } \\
\text { nativas. Intersección de buffer con Unidades } \\
\text { de Análisis (Catastro de Bosque Nativo e } \\
\text { Inventario Forestal) }\end{array}$ \\
\hline $\begin{array}{l}\text { Riqueza de especies claves } \\
\text { en la unidad de análisis. }\end{array}$ & $\begin{array}{l}\text { Número de especies } \\
\text { forestales claves presentes } \\
\text { en la unidad de análisis }\end{array}$ & $\begin{array}{l}\text { Global Index of Vegetation plot Databases } \\
\text { (SA-CL-002, 2016), Catastro de Bosque } \\
\text { Nativo (CONAF, 2014) e Inventario forestal } \\
\text { del Instituto Forestal (INFOR, 2010) }\end{array}$ & $\begin{array}{l}\text { Creación de áreas buffer de } 10 \text { metros } \\
\text { para cada dato de riqueza de especies } \\
\text { claves. Intersección de buffer con Unidades } \\
\text { de Análisis (Catastro de Bosque Nativo e } \\
\text { Inventario Forestal) }\end{array}$ \\
\hline
\end{tabular}

Fuente: Elaboracion propia.

Describa brevemente qué criterios ecológicos consideraría usted relevante para priorizar la recuperación de Bosque Templado Lluvioso Valdiviano intervenido, y ¿Qué especies forestales del Bosque Templado Lluvioso Valdiviano usted consideraría claves ecológicamente?.

Para la primera pregunta, el objetivo fue reconocer criterios ecológicos que no fueron señalados en la revisión bibliográfica y que son atingentes al territorio. Mientras tanto, el propósito de la segunda pregunta fue obtener un listado de especies forestales clave en el Bosque Templado Lluvioso Valdiviano para generar un mapa regional considerando la frecuencia de respuestas.
Además, se solicitó a los expertos realizar la comparación por pares de cada uno de los criterios ecológicos. A estas respuestas se agregaron los juicios individuales mediante la valoración de los criterios ecológicos por experto, cuyo objetivo fue obtener la valoración y jerarquía de cada criterio ecológico seleccionado en la revisión bibliográfica.

Para la jerarquización y priorización de los criterios ecológicos, se utilizó el método de Evaluación Multicriterio expuesto por Saaty (2008) donde se generaron las variables geográficas representativas para cada criterio ecológico, centrándose en las Unidades de Análisis pertenecientes a la Región de Los Ríos. Cada variable se estandarizó 


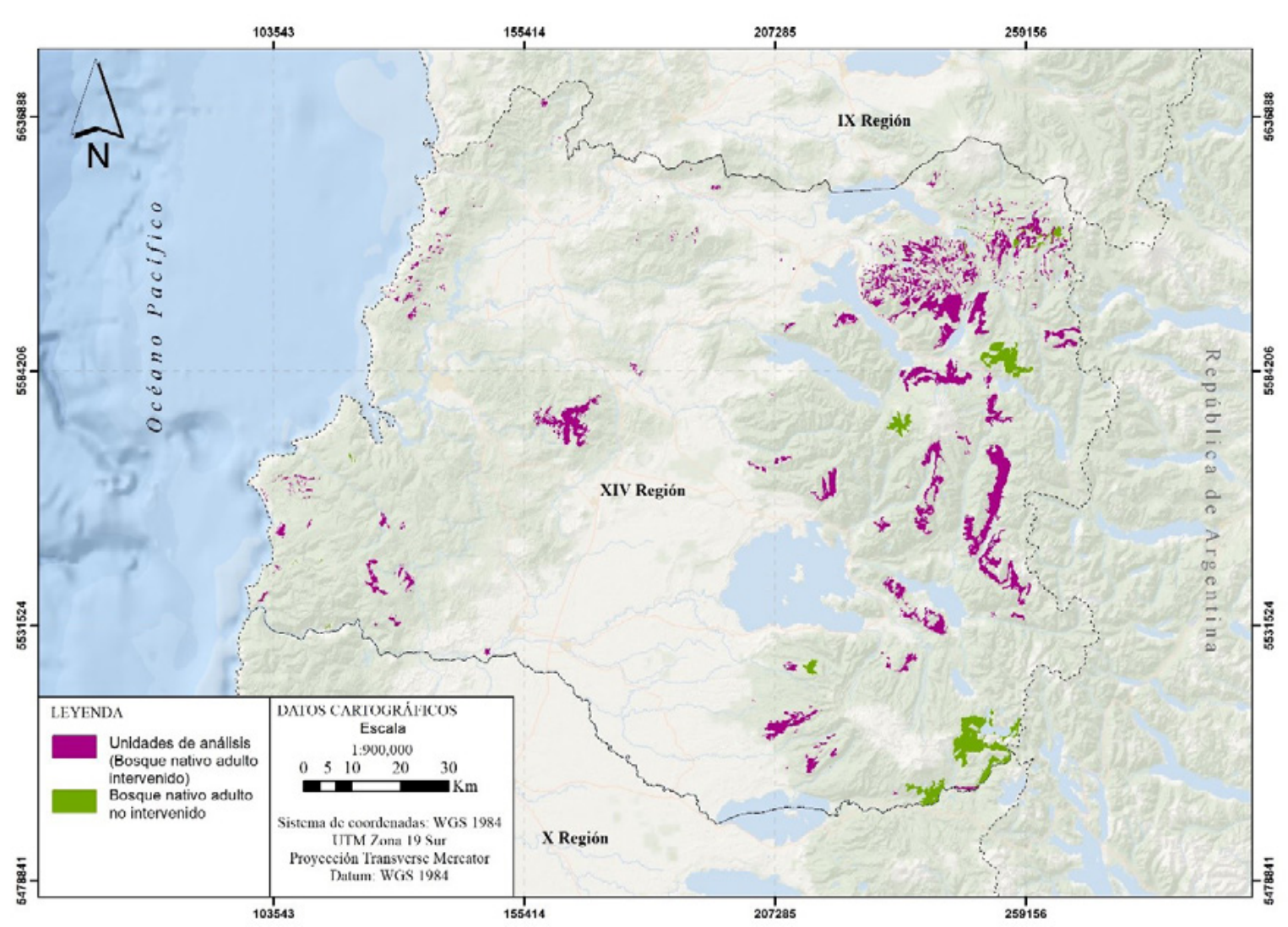

Figura 1. Distribución espacial de las unidades de análisis en la Región de Los Ríos y el bosque nativo adulto no intervenido. Fuente: Elaboración propia.

con valores discretos que oscilaron entre 1 y 3 (Eastman, 2006). Posteriormente, se construyó el índice ecológico para la priorización de bosque nativo intervenido usando un Sistema de Información Geográfica (SIG), ingresando como insumos las coberturas reclasificadas (x) y sus pesos relativos (w), según la siguiente ecuación:

$$
\text { IEBN: } \sum_{\mathrm{i}=1}^{\mathrm{n}}\left(\mathrm{w}_{\mathrm{i}} \cdot \mathrm{x}_{\mathrm{i}}\right)
$$

Ecuación 1. Ecuación para la elaboración del índice de ecológico para la priorización de bosque nativo intervenido.

Los valores de priorización se determinaron a partir de la re-clasificación de los valores del índice mediante rangos cualificados como alto, medio o bajo. Los valores mínimos y máximos de cada rango se establecieron según los cuantiles de los valores del índice. El establecimiento de rangos a partir de terciles de distribución se realizó luego de aplicar el test de Shapiro-Wilk y de definir que los valores del índice poseían una distribución normal (Taucher, 1999).
Finalmente, con los valores de prioridad se generó un mapa semáforo con zonas prioritarias para la recuperación de bosque nativo intervenido en la Región de Los Ríos, cuya escala es de 1:50.000.

\section{Resultados}

\section{Unidades de análisis}

Se distinguieron 85 unidades de análisis pertenecientes al BTLV, las cuales se distribuyen principalmente en la precordillera andina de la Región, seguido por la Cordillera de la Costa y una menor superficie en la depresión intermedia. A nivel local, la comuna con mayor superficie con bosque nativo adulto intervenido fue Panguipulli (44,96\%), luego Futrono $(27,18 \%)$ y Lago Ranco $(5,86 \%)$. Las unidades de análisis de bosque nativo adulto intervenido cubrieron 54.484 hectáreas, es decir, que el $82,5 \%$ del total del bosque nativo adulto de la Región de Los Ríos presentó intervención antrópica (figura 1). 


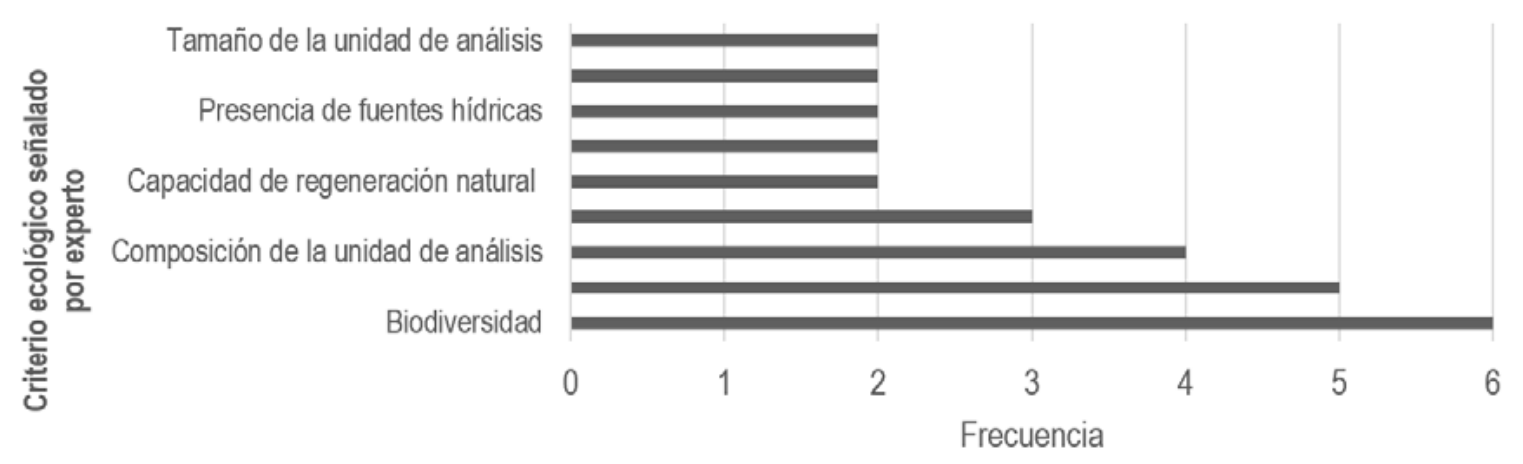

Figura 2. Frecuencia de criterios ecológicos señalados por expertos de acuerdo con la información cualitativa generada para la priorización de criterios ecológicos. Fuente: Elaboración propia.

\section{Selección de criterios ecológicos}

Los criterios ecológicos que han sido comúnmente utilizados para establecer áreas prioritarias para la conservación, preservación y/o recuperación de bosque nativo, además de zonificaciones o valoraciones ecológicas, la respectiva variable e información cartográfica de cada uno de ellos, además de la metodología GIS se presentan en la tabla 1 .

\section{Valoración de criterios ecológicos.}

La información cualitativa para la priorización de criterios ecológicos recopilada a través de las preguntas es presentada a continuación:

Describa brevemente qué criterios ecológicos consideraría usted relevante para priorizar la recuperación de Bosque Templado Lluvioso Valdiviano intervenido. En esta pregunta se señalaron 30 criterios diferentes, de los cuales nueve tuvieron una frecuencia de respuesta mayor a dos, es decir, que a lo menos dos expertos sostuvieron que este criterio es relevante al momento de priorizar un sitio para la recuperación del bosque nativo intervenido (figura 2).

En relación con la figura 2, existen ciertos criterios que son integrados en la evaluación multicriterio debido a que fueron documentados en la literatura y que son validados por los expertos participantes, estos criterios fueron: estructura de la unidad de análisis, presencia de especies amenazadas, conectividad de la unidad de análisis y tamaño de la unidad de análisis. Los criterios ecológicos seleccionados para la Evaluación Multicriterio que son análogos a los criterios indicados por los expertos se presentan en la tabla 2.
Tabla 2

Analogía de los criterios ecológicos propuestos para la EMC y los indicados por los expertos.

\begin{tabular}{ll}
\hline $\begin{array}{l}\text { Criterio ecológico señalado por } \\
\text { experto }\end{array}$ & $\begin{array}{l}\text { Criterio ecológico seleccionado } \\
\text { para la EMC }\end{array}$ \\
\hline $\begin{array}{l}\text { Estructura de la unidad de } \\
\text { análisis }\end{array}$ & $\begin{array}{l}\text { Estructura de la unidad de } \\
\text { análisis }\end{array}$ \\
\hline $\begin{array}{l}\text { Presencia de especies } \\
\text { amenazadas }\end{array}$ & $\begin{array}{l}\text { Riqueza de especies en } \\
\text { categoría de conservación en la } \\
\text { unidad de análisis. }\end{array}$ \\
\hline $\begin{array}{l}\text { Conectividad de la unidad de } \\
\text { análisis }\end{array}$ & $\begin{array}{l}\text { Cercanía de la unidad de } \\
\text { análisis con otros bosques } \\
\text { nativos. } \\
\text { Cercanía de la unidad de } \\
\text { análisis con el área protegida } \\
\text { más cercana. }\end{array}$ \\
\hline Tamaño de la unidad de análisis & Tamaño de la unidad de análisis \\
\hline
\end{tabular}

Fuente: Elaboración propia.

Se evidenció por los expertos participantes que la presencia de fuentes hídricas, tales como cursos o cuerpos de agua, es relevante al momento de priorizar un bosque nativo. Sin embargo, en la literatura utilizada no se señalaba como un criterio ecológico.

¿Qué especies forestales del Bosque Templado Lluvioso Valdiviano usted consideraría claves ecológicamente? Las especies clave mencionadas en los cuestionarios suman 14 especies en total. Sin embargo, sólo seis de ellas fueron 


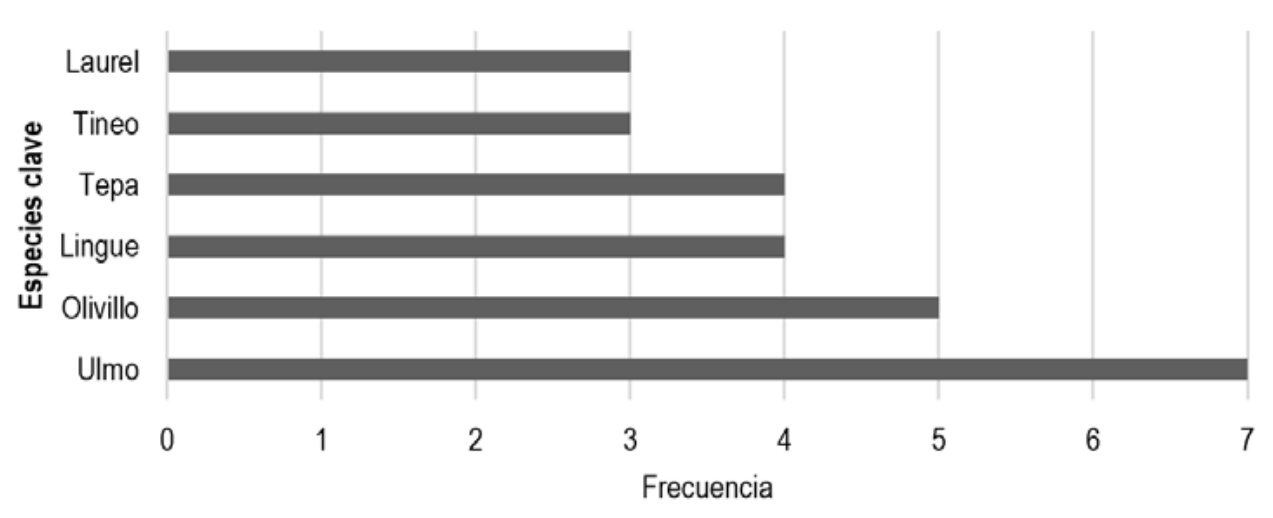

Figura 3. Frecuencia de especies claves señaladas por los expertos de acuerdo con la información cualitativa generada para la priorización de criterios ecológicos. Fuente: Elaboración propia

seleccionadas para la construcción del criterio "Riqueza de especies en la unidad de análisis", debido a que se presentan con mayor frecuencia en las respuestas (figura 3). Las especies clave identificadas por los expertos fueron: laurel (Laurelia sempervirens (Ruiz et Pav.) Tul.), tineo (Weinmannia trichosperma Cav.), tepa (Laureliopsis philippiana (Looser) Schodde), lingue (Persea lingue (Ruiz et Pav.) Nees), olivillo (Aextoxicon punctatum Ruiz et Pav.) y ulmo (Eucryphia cordifolia Cav.).

Según la figura 3, la especie clave que obtuvo una mayor frecuencia fue el ulmo. Su elección se debe a que la especie cumple un importante rol en los bosques templados como sostenedor de la biodiversidad para especies nativas (Godoy, Ramírez, Figueroa \& Hauenstein, 1981; González, Donoso, \& Fraver, 1997, Díaz, Sieving, Peña-Foxon, Larraín \& Armesto, 2010; Smith-Ramírez et al. 2014). Además, es reconocida por su rápida capacidad de regenerarse vegetativamente a partir de tocones (Donoso, 1989, Harmon et al., 2004), por lo que esta especie se perfila como promisoria para el manejo silvicultural futuro del bosque (Donoso, 1989), permitiendo dirigir las acciones de recuperación del bosque en el que está presente (Armesto \& Smith-Ramírez, 1994).

Otras de las especies clave señaladas son el laurel y el olivillo, para las cuales también se menciona un rol ecológico importante (González et al., 1997), debido a que conforman el bosque de especies tolerantes o de tolerancia media-baja a la sombra en las etapas iniciales de la sucesión forestal (Donoso, 1989), y la rica asociación con especies epifitas que tienen sus bosques (Díaz et al. 2010). Para el caso del olivillo, la condición de sostenedor de biodiversidad epifita lo posiciona como una especie ecológicamente relevante en los bosques templados valdivianos (Díaz et al. 2010), ya que en estas comunidades se refugia una importante biodiversidad de fauna vertebrada e invertebrada (Díaz, Armesto, Reid, Sieving \& Willson, 2005), además que la especie establece interacciones mutualistas con fauna nativa (Salvande, Figueroa, \& Armesto, 2011). Díaz et al. (2010) señala que la presencia de Olivillo en los bosques nativos no sólo contribuye a la productividad de estos ecosistemas, sino que también provee de importantes servicios ecosistémicos.

En el caso de lingue se ha descrito que la reducción de su distribución geográfica se debe particularmente por la habilitación de tierras agrícolas y ganaderas (San Martín, Ramírez, Figueroa \& Ojeda, 1991). Desde el punto de vista ecológico, la importancia del lingue se releva a las interacciones mutualistas que mantiene con especies de fauna nativa, como por ejemplo con el zorzal patagónico (Turdus falcklandii magellanicus King) y el ratoncito lanudo (Abrothrix olivacea Waterhouse) (Gho-Illanes, Smith-Ramírez, Vásquez \& Díaz, 2015).

Finalmente, la especie tineo se destaca por su importante capacidad de regeneración vegetativa (Donoso, 1989, Harmon et al., 2004), por lo que la presencia de la especie en unidades de análisis facilita la recuperación del bosque (Armesto \& Smith-Ramírez, 1994).

\section{Evaluación multicriterio}

En la tabla 3 se pueden apreciar los rangos de valores de cada criterio y su contribución para la priorización ecológica. La contribución alta fue representada numéricamente con valor uno, la media con un dos y la baja con valor tres. 
Tabla 3

Rangos de contribución a la priorización ecológica de bosque nativo intervenido para cada criterio ecológico.

\begin{tabular}{|c|c|c|c|}
\hline \multirow{2}{*}{ Criterio } & \multicolumn{3}{|c|}{ Contribución a la priorización ecológica } \\
\hline & Alta & Media & Bajo \\
\hline $\begin{array}{l}\text { Cercanía de la unidad de análisis con } \\
\text { el área protegida más cercana (metros) }\end{array}$ & $7.619-22.588$ & $2.581-7.618$ & $0-2.580$ \\
\hline $\begin{array}{l}\text { Riqueza de especies en categoría de } \\
\text { conservación en la unidad de análisis. }\end{array}$ & 4 especies & 1 especies & 0 especies \\
\hline $\begin{array}{l}\text { Tamaño de la unidad de análisis } \\
\text { (hectáreas) }\end{array}$ & $0-79$ & $80-436$ & $437-4.234$ \\
\hline $\begin{array}{l}\text { Cercanía de la unidad de análisis con } \\
\text { otros bosques nativos (metros) }\end{array}$ & $2.921-12.735$ & $1-2.920$ & 0 \\
\hline Estructura de la unidad de análisis. & Bosque nativo adulto & Bosque nativo achaparrado & Bosque nativo adulto-renoval \\
\hline $\begin{array}{l}\text { Riqueza de especies nativas en la unidad } \\
\text { de análisis. }\end{array}$ & 11 - 29 especies & $10-8$ especies & 7 - 1 especie(s) \\
\hline $\begin{array}{l}\text { Riqueza de especies claves en la unidad } \\
\text { de análisis. }\end{array}$ & 6 - 5 especies & 4 especies & 3 - 0 especie(s) \\
\hline
\end{tabular}

Fuente: Elaboración propia.

Posterior a la integración de los juicios individuales de cada experto, se calcularon los valores del vector prioridad dando como resultado el peso relativo para cada criterio y el valor del cociente de consistencia (RC), los cuales son presentados en la tabla 4 .

\section{Tabla 4}

Peso relativo de cada criterio ecológico según la integración de los juicios individuales.

\begin{tabular}{lll}
\hline $\begin{array}{l}\mathbf{N}^{\circ} \\
\text { Criterio }\end{array}$ & Criterio & $\begin{array}{l}\text { Peso } \\
\text { Relativo (\%) }\end{array}$ \\
\hline C1 & $\begin{array}{l}\text { Cercanía de la unidad de análisis con } \\
\text { el área protegida más cercana. }\end{array}$ & 12 \\
\hline C2 & $\begin{array}{l}\text { Riqueza de especies en categoría de } \\
\text { conservación en la unidad de análisis. }\end{array}$ & 25 \\
\hline C3 & $\begin{array}{l}\text { Cercanía de la unidad de análisis con } \\
\text { otros bosques nativos. }\end{array}$ & 9 \\
\hline C4 & Tamaño de la unidad de análisis. & 20 \\
\hline C5 & Estructura de la unidad de análisis. & 11 \\
\hline
\end{tabular}

\begin{tabular}{lll}
\hline $\begin{array}{l}\mathbf{N}^{\circ} \\
\text { Criterio }\end{array}$ & Criterio & $\begin{array}{l}\text { Peso } \\
\text { Relativo (\%) }\end{array}$ \\
\hline C6 & $\begin{array}{l}\text { Riqueza de especies nativas en la } \\
\text { unidad de análisis. }\end{array}$ & 9 \\
\hline C7 & $\begin{array}{l}\text { Riqueza de especies claves en la } \\
\text { unidad de análisis. }\end{array}$ & 14 \\
\hline
\end{tabular}

Fuente: Elaboración propia.

Según lo anterior, los criterios con mayor peso fueron las especies en categoría de conservación presentes en la unidad de análisis, le sigue el tamaño de la unidad de análisis y la riqueza de especies claves en la unidad de análisis. Por el contrario, los criterios con menor contribución fueron la cercanía de la unidad de análisis con otros boques nativos y la riqueza de especies nativas en la unidad de análisis.

El modelo de evaluación multicriterio obtuvo un valor de consistencia de 0,1 indicando una consistencia razonable de los juicios, por lo que se validaron los pesos relativos de cada criterio ecológico. De acuerdo al peso relativo de cada criterio ecológico se pudo establecer el siguiente 
índice de priorización (índice ecológico para la priorización de bosque nativo intervenido de la Región de Los Ríos):

$$
\begin{aligned}
& \text { IEBN: } \mathrm{C} 1 * 0,12+\mathrm{C} 2 * 0,25+\mathrm{C} 3 * 0,9+\mathrm{C} 4 * 0,2+\mathrm{C} 5 * 0,11+ \\
& \mathrm{C} 6 * 0,9+\mathrm{C} 7 * 0,14
\end{aligned}
$$

Los valores del IEBN permitieron estimar que la muestra tuvo una distribución normal (prueba de normalidad de Shapiro-Wilk, $P=0,4767$, figura 4 ). Tales valores al ser re-clasificados de acuerdo a tres cuantiles, proporcionaron los valores de priorización.

A partir de los resultados de los valores de prioridad estimados por el IEBN la Región de Los Ríos se pudo establecer que, de las 85 unidades de análisis: 31 tienen una alta prioridad a ser recuperadas (valores de prioridad entre 1,5 a 2,08), 25 prioridad media (valores de prioridad entre 2,1 a 2,27) y 29 con prioridad baja (valores de prioridad entre 2,28 a 2,69), cuyas superficies son de $6.582,20.150$ y 27.750 hectáreas respectivamente. La superficie con máxima prioridad corresponde al $12 \%$ de

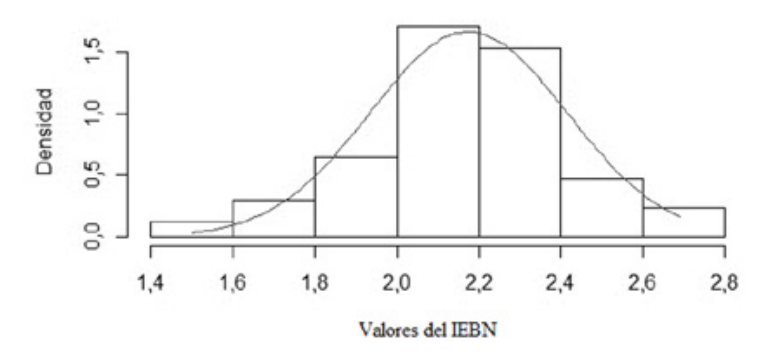

Figura 4. Distribución normal de frecuencias de los valores del IEBN. Donde el eje " $x$ " representa los valores del IEBN, y el eje " $y$ ": "Densidad" representa la densidad de frecuencias de los valores del IEBN. Fuente: Elaboración propia.

la superficie total de las unidades de análisis, la cual se distribuye principalmente en las comunas de Panguipulli, La Unión y Mariquina (figura 5).

En relación con la protección legal que tienen los sitios prioritarios, 29 de ellos se ubicaron dentro de un área protegida, siendo el $34 \%$ de las unidades de análisis. De estas 29 unidades de análisis, ocho tienen máxima prioridad

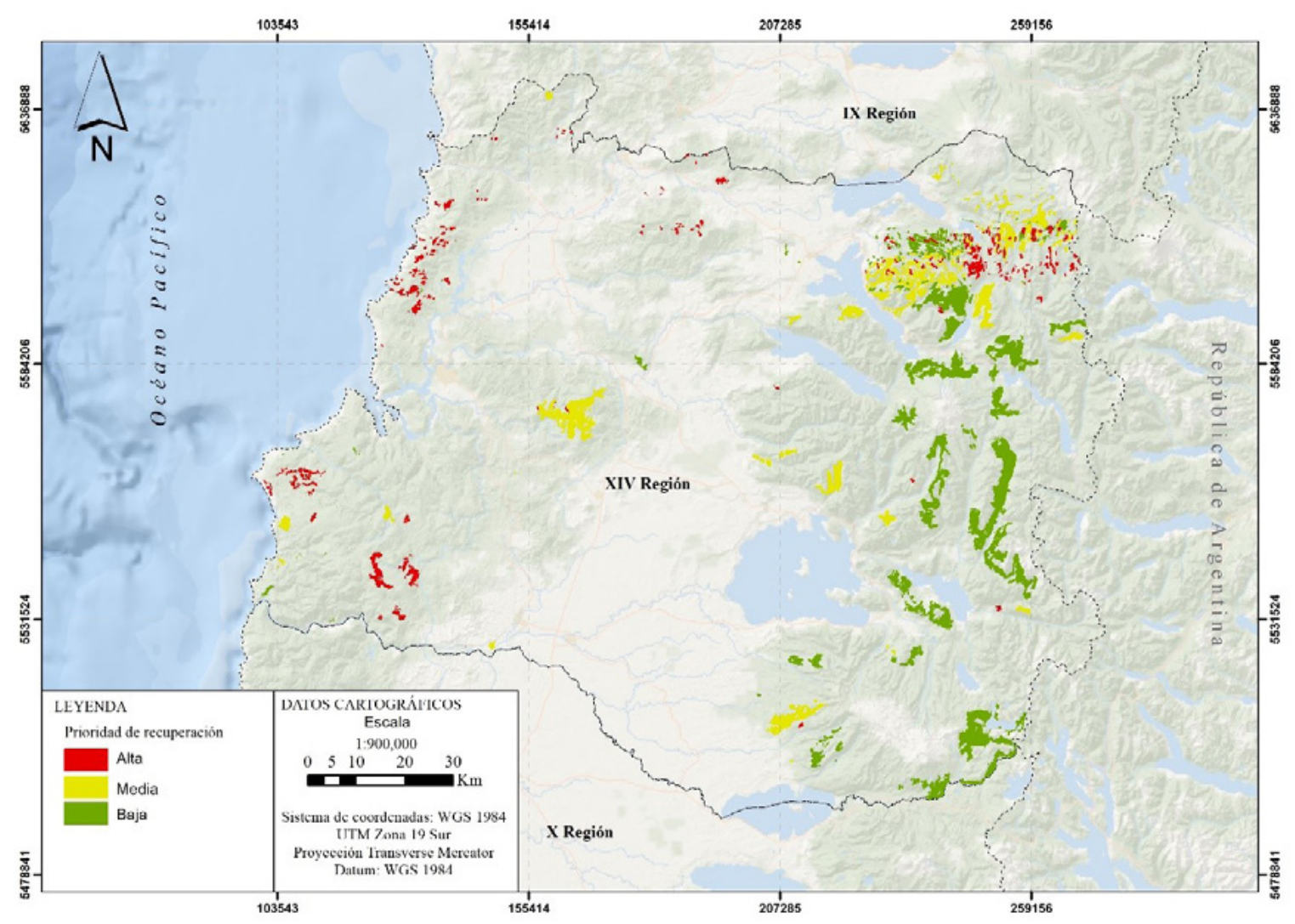

Figura 5. Ubicación espacial de los sitios prioritarios para la recuperación de bosque nativo intervenido de la Región de Los Ríos. Fuente: Elaboración propia. 
de recuperar, abarcando una extensión de 664,6 hectáreas, lo que significa que el $10 \%$ de la superficie con máxima prioridad se emplaza bajo una figura de protección legal.

\section{Discusión}

La priorización de sitios para recuperación de bosque nativo intervenido utilizando evaluación multicriterio permite una aproximación objetiva de sitios potenciales a priorizar, ya que las propuestas se basan en alternativas que pueden ser medidas de acuerdo al valor de consistencia (Phua \& Minowa, 2005). Considerando lo anterior, en la presente investigación se determina a través de la EMC que los criterios con mayor prioridad son la riqueza de especies en categoría de conservación y el tamaño de la unidad de análisis. El primero obtiene la mayor prioridad de acuerdo con la agregación de los juicios por expertos (peso relativo del $25 \%$ ), debido a que este tipo de especies son altamente vulnerables a los procesos de degradación forestal (Altamirano, Echeverría \& Lara, 2007). Por lo tanto, a medida que las unidades de análisis presentan una mayor riqueza de especies amenazadas, las unidades tendrán mayor prioridad. En este contexto, la presencia de especies claves en la unidad a recuperar se exhibe como opción complementaria para dirigir las acciones de protección debido a la importancia de estas especies para los ecosistemas (Muñoz et al., 2013). Sin embargo, es relevante destacar que las especies amenazadas no forman parte de las especies claves listadas por los expertos, por ello, las acciones de recuperación deberán integrar ambos criterios. Para el segundo criterio: tamaño de la unidad de análisis (peso relativo del 20\%), Sutherland et al. (2006) señala que a medida que los parches de bosque son más grandes, habrá una mayor conectividad en comparación con parches más pequeños, por lo que las unidades de análisis con superficies reducidas tendrían una mayor prioridad de recuperación debido a su aislamiento. Además, los impactos de los agentes de degradación serían mayores en superficies de bosques nativos menos extensas (Zamorano-Elgueta, 2014), lo que se vería reflejado en que la regeneración de especies nativas disminuye rápidamente en superficies de menor tamaño (Zamorano-Elgueta, 2014).

En relación con el criterio cercanía de la unidad de análisis con el área protegida más cercana, Orsi \& Geneletti (2010) describe que las áreas protegidas funcionan como zonas de protección frente a disturbios externos y que, además, son una fuente de biodiversidad, por lo que la distancia a dichas áreas es considerada como una variable clave al momento de proponer sitios ecológicamente prioritarios. Según los resultados, el 10\% de los sitios con mayor prioridad se encuentran cercanos a un área protegida, por lo que el resto de las unidades de análisis con alta prioridad requieren medidas urgentes para su recuperación y así evitar una mayor degradación forestal.

En cuanto a los resultados de los cuestionarios, la cercanía a la fuente hídrica se menciona como un criterio relevante al momento de priorizar un bosque por parte de los expertos, pero éste no se considera en la EMC ya que no se presenta como un criterio ecológico en las referencias bibliográficas consultadas. Sin embargo, las unidades de análisis con presencia de fuentes hídricas debiesen ser prioritarias, ya que los bosques ribereños aumentan la conectividad entre los paisajes, son un refugio de fauna y regulan la temperatura y productividad del agua (Romero, Cozano, Gangas \& Naulin, 2014), por lo que se recomienda que estudios posteriores integren este criterio dentro de la EMC.

Las áreas con máxima prioridad conforman el $12 \%$ de los bosques nativos adultos intervenidos, las que se encuentran ubicadas principalmente en las comunas de Panguipulli, La Unión y Mariquina. En Panguipulli, se identifica que existe una matriz en el extremo noreste de la comuna que engloba las tres prioridades (alta, media y baja). Estos patrones de distribución se pueden explicar por la calidad y la cantidad de las fuentes de información geográficas del criterio riqueza de especies en categoría de conservación. En este sentido, la escasa información pública sobre las localidades donde ocurren especies en categoría de conservación sugiere que podrían presentarse áreas prioritarias sub-valoradas. Por lo tanto, se reconoce la necesidad de realizar un monitoreo in situ para expandir y validar los resultados obtenidos de riqueza de especies presentes en las unidades de análisis.

Considerando el alto porcentaje de bosque nativo adulto intervenido encontrado en esta investigación ( $82,5 \%$ del total de bosque nativo adulto), es indispensable evitar el avance del proceso de degradación hacia bosques maduros altamente prioritarios de preservar ( $12 \%$ de la superficie prioritaria), así como también proteger aquellos bosques que no han sido declarados en degradación $(17,5 \% \mathrm{del}$ total de bosque nativo adulto), ya que presentan una importancia ecológica que debe ser resguardada. Además, se debe establecer claramente los actuales causantes de degradación de bosque nativo adulto, y en base a esto, determinar si se puede modelar y espacializar estas causas para integrarlos como limitantes en los modelos de evaluación multicriterio. Debido a lo anterior, al momento de decidir el tipo de técnica de recuperación a utilizar, se recomienda buscar alternativas apropiadas al contexto territorial en que se inserta cada unidad de 
análisis de bosque nativo intervenido, particularmente buscando soluciones locales para cada área prioritaria y considerando una clara estrategia de financiamiento, poniendo énfasis en aquellas comunas que presentan mayor superficie prioritaria (Panquipulli y La Unión) y que no presentan alguna figura de protección legal. Además, de acuerdo con Sabogal (2008), se sugiere que cualquier planificación para las áreas a recuperar sea bajo un paradigma adaptativo y multidimensional, es decir, integrando aquellos actores que son claves para el territorio y considerando el dinamismo del ecosistema forestal. De esta forma, la presente investigación proporciona un insumo para evaluar y dirigir futuras acciones de recuperación hacia aquellos sitios ecológicamente prioritarios.

Finalmente, se destaca que las fuentes de información utilizadas en esta investigación son de carácter público, por lo que los datos geográficos pueden ser integrados por distintos organismos públicos para establecer planes, programas y políticas relacionadas con la conservación y protección de la biodiversidad. De esta forma, la metodología presentada representa una alternativa para la determinación rápida y de bajo costo de áreas prioritarias para la recuperación del bosque nativo intervenido en otras regiones del país.

\section{Conclusiones}

La presente investigación determinó que en las comunas de Panguipulli y La Unión existe una mayor superficie de zonas prioritarias para la recuperación del bosque nativo adulto intervenido, debido a que se presentan criterios con mayor peso relativo en la EMC, tales como: la riqueza de especies en categoría de conservación y el tamaño de las unidades de análisis. Estos criterios al ser integrados mediante el índice ecológico sugieren zonas con diferentes prioridades de recuperación, las cuales se caracterizan por su importancia ecológica en base a opinión experta. Esta información, permite orientar espacialmente a los diferentes organismos encargados de proteger el patrimonio natural sobre los sitios que requieren recuperar sus bosques nativos con mayor urgencia. Sin embargo, es necesario considerar que el territorio es multidimensional, por lo que la integración equilibrada de los múltiples usos, espacios públicos, residenciales, actividades productivas, áreas protegidas, entre otros, permitiría que las acciones de recuperación sean realmente efectivas.

Es por ello que se propone mantener y extender la participación de los actores atingentes al territorio, así como también integrar aquellos criterios geográficos de otras dimensiones en la EMC, por ejemplo, criterios sociales, económicos e institucionales, para que así las técnicas de recuperación de bosque nativo intervenido tengan concordancia con la realidad local.

\section{Referencias}

Aizen, M. \& Ezcurra, C. (1998). High incidence of plantanimal mutualisms in the woody flora of the temperate forest of southern South America: biogeographical origin and present ecological significance. Ecología Austral, 8(2), 217-236.

Altamirano, A., Echeverría, C., \& Lara, A. (2007). Efecto de la fragmentación forestal sobre la estructura vegetacional de las poblaciones amenazadas de Legrandia concinna (Myrtaceae) del centro-sur de Chile. Revista Chilena de Historia Natural, 80(1), 27-42. https://dx.doi. org/10.4067/S0716-078X2007000100003

Argibay, J.C. (2009). Muestra en investigación cuantitativa. Subjetividad y procesos cognitivos, 13(1), 13-29.

Armesto, J. \& Smith-Ramírez, C. (1994). Criterios ecológicos para el manejo del bosque nativo. Ciencia y Ambiente, 10(3), 64-71.

Armesto, J.,Villagrán, C. \& Arroyo, M. (1996). Los bosques templados del sur de Chile y Argentina: Una isla biogeográfica. En J. Armesto, C. Villagrán y M. Arroyo (Eds.), Ecología de los bosques nativos de Chile (pp. 32-46). Santiago, Chile: Editorial Universitaria.

Baldini, A. \& Pancel, L. (2000). Agentes de daño en el bosque nativo. Santiago, Chile: Editorial Universitaria.

Bannister, J.R., González, M., Little, C., Gutiérrez, A.G., Donoso, P., Mujica, R., ... Zambrano, C. (2013). Experiencias de restauración en los bosques nativos del sur de Chile: Una mirada desde la Isla Grande de Chiloé. Revista Bosque Nativo, 52, 35-43.

Branquart, E.; Verheyen, K. \& Latham, J. (2008). Selection criteria of protected forest areas in Europe: The theory and the real world. Biological Conservation, 141(1), 2795-2806. https://doi.org/10.1016/j.biocon.2008.08.015

Camus, P. (2008). La intervención de la selva austral: Bosques y tierras despejadas en la cuenca del río Valdivia (Siglos XVI-XIX). Revista de geografía de Norte Grande, 40, 5-22. http://dx.doi.org/10.4067/ S0718-34022008000200001 
Corporación Nacional Forestal [CONAF]. (2014). Monitoreo de Cambios, Corrección Cartográfica y Actualización del Catastro de los Recursos Vegetacionales Nativos de la región de Los Ríos (Informe final). Valdivia: Geomática UACh Valdivia. Recuperado de http:// biblioteca.digital.gob.cl/handle/123456789/2340

Comisión Nacional del Medio Ambiente [CONAMA]. (2010). Estrategia de Conservación de la Biodiversidad de la Región de Los Ríos. Valdivia: CONAMA. Recuperado de http://catalogador.mma.gob.cl:8080/geonetwork/srv/ spa/resources.get?uuid=fb462f46-6575-40a9-82508346ddebe5e7\&fname $=$ ERB LOS R\%C3\%8DOS. pdf\&access $=$ public

Díaz, I.A., Armesto, J.J., Reid, S., Sieving, K.E., \& Willson, M.F. (2005). Linking forest structure and composition: avian diversity in successional forests of Chiloé Island, Chile. Biological Conservation, 123(1), 91-101. https://doi.org/10.1016/j.biocon.2004.10.011

Díaz, I.A., Sieving, K.E., Peña-Foxon, M.E., Larraín, J., \& Armesto, J.J. (2010). Epiphyte diversity and biomass loads of canopy amergent tres in Chilean temperate rain forests: A neglected functional component. Forest Ecology and Management, 259(8), 1.490-1.501. https:// doi.org/10.1016/j.foreco.2010.01.025

Donoso, C. (1989). Antecedentes básicos para la silvicultura del tipo forestal siempreverde. Bosque (Valdivia), 10(1), 37-53.

Eastman, J. (2006). IDRISI Andes. Guide to GIS and Image Processing. Worcester, MA: Clark Labs, Clark University.

Echeverría, C., Newton, A.C., Lara, A., Benayas, J.M.R., \& Coomes, D.A. (2007). Impacts of forest fragmentation on species composition and forest structure in the temperate landscape of southern Chile. Global Ecology and Biogeography, 16(4), 426-439. https://doi.org/10.1111/ j.1466-8238.2007.00311.x

Fernández, I., Morales, N., Olivares, L., Salvatierra, J., Gómez, M., \& Montenegro, G. (2010). Restauración ecológica para ecosistemas nativos afectados por incendios forestales. Santiago de Chile: Gráfica LOM.

Gajardo, R. (1994). La vegetación natural de Chile: clasificación y distribución geográfica. Santiago de Chile: Editorial Universitaria.
Ghazoul, J., Burivalova, Z., García-Ulloa, J., \& King, L.A. (2015). Conceptualizing Forest Degradation. Trends in Ecology \& Evolution, 30(10), 622-632. https://oi. org/10.1016/j.tree.2015.08.001

Gho-Illanes, D., Smith-Ramírez, C., Vásquez, I.A., \& Díaz, I. (2015). Frugivory of Persea lingue (Lauraceae) and its effect on seed germination in southern Chile. Gayana Botánica, 72(2), 250-257.

Global Index of Vegetation Plot Databases [GIVD]. (2016). SA-CL-002 - SSAForests_Plots_db. Recuperado de: http://www.givd.info/ID/SA-CL-002.

Godoy, R., Ramírez, C., Figueroa, H., \& Hauenstein, E. (1981). Estudios ecosociológicos en Pteridófitos de comunidades boscosas valdivianas, Chile. Bosque, 4(1), 12-24.

Gómez Delgado, M. \& Barredo Cano, J. (2005). Sistemas de información geográfica y evaluación multicriterio en la ordenación del territorio. Madrid: Ed. RA-MA.

González, M., Donoso, C., \& Fraver, S. (1997). Respuesta inicial de Eucryphia cordifolia Cav., Laurelia sempervirens R., et P. Tul. y Aextoxicon punctatum R. et $\mathrm{P}$. en plantaciones mixtas en sectores recientemente florecidos con Chusquea quila Kunth en el centro-sur de Chile. Bosque, 18(1), 53-59.

Harmon, M., Franklin, J.F., Swanson, F.J., Sollins, P., Gregory, S.V., Lattin, J.D., ... Cummins, K.W. (2004). Ecology of coarse woody debris in temperate ecosystems. Advances in Ecological Research, 34, 59-234. https:// doi.org/10.1016/S0065-2504(03)34002-4

Hernández, R., Fernández, C., \& Baptista, P. (2010). Metodología de la investigación. D.F., México: McGrawHill/Interamericana Editores, S.A. de CV.

Instituto Forestal [INFOR]. (2010). Los recursos forestales en Chile: Inventario continuo de bosques nativos y actualización de plantaciones forestales (Informe final). Santiago: INFOR. Recuperado de https://bibliotecadigital. infor.cl/handle/20.500.12220/17877

Ministerio del Medio Ambiente [MMA]. Gobierno de Chile (2011). Informe del Estado del Medio Ambiente. Santiago: MMA. Recuperado de http://bibliotecadigital. ciren.cl/handle/123456789/6883

Muñoz, F., Muñoz, C., Uribe, M., Martín, M.A., Molina, J.R., Herrera, M.A., ... Martín, L.M. (2013). Composición, 
estructura y diversidad de poblaciones de Nothofagus glauca ubicadas en la zona mediterránea de Chile. Gayana Botánica, 70(1), 82-91. https://dx.doi.org/10.4067/ s0717-66432013000100009

Myers, N., Mittermeier, R.A., Mittermeier, C.G., da Fonseca, G.A.B., \& Kent, J. (2000). Biodiversity hotspots for conservation priorities. Nature, 403, 853-858. https:// doi.org/10.1038/35002501

Navarro, G., De la Barra, N., Rumiz, D., y Wanderley, F. (2008). Criterios para evaluar el estado actual de conservación y degradación de los bosques de Bolivia. Revista boliviana de ecología y conservación ambiental, 22, $01-18$.

Organización Internacional de las Maderas Tropicales [OIMT]. (2002). Directrices de la OIMT para la restauración, ordenación y rehabilitación de bosques tropicales secundarios y degradados (Serie de políticas forestales $\left.\mathrm{N}^{\circ} 13\right)$. Recuperado de http://www.unsa.edu. ar/bibnat/openaccess/ps13s.pdf

Olson, D.M. \& Dinerstein, E. (2002). The Global 200: Priority Ecoregions for Global Conservation. Annals of the Missouri Botanical Garden, 89(2), 199-224. https://doi.org/10.2307/3298564

Orsi, F., Geneletti, D., \& Newton, A.C. (2011). Towards a common set of criteria and indicators to identify forest restoration priorities: An expert panel-based approach. Ecological Indicators, 11(2), 337-347. https://doi. org/10.1016/j.ecolind.2010.06.001

Orsi, F. \& Geneletti, D. (2010). Identifying priority areas for Forest Landscape Restoration in Chiapas (Mexico): An operational approach combining ecological and socioeconomic criteria. Landscape and Urban Planning, 94(1), 20-30. https://doi.org/10.1016/j. landurbplan.2009.07.014

Phua, M-H. \& Minowa, M. (2005). A GIS-based multicriteria decision making approach to forest conservation planning at a landscape scale: a case study in the Kinabalu Area, Sabah, Malaysia. Journal Landscape and Urban Planning, 71(2-4), 207-222. https://doi. org/10.1016/j.landurbplan.2004.03.004

Quiroz, C; A. Pauchard; A. Marticorena \& Cavieres, L. (2009). Manual de plantas invasoras del centro-sur de Chile. Concepción: LIB. Recuperado de http://www.lib. udec.cl/wp-content/uploads/2017/11/plantas-invasoras.pdf
Rojas, Y., Loguercio, G., Nieto, V., \& Bahamondez, C. (2011). Análisis de la degradación forestal en el marco de REDD+. Santiago, Chile: INFOR.

Romero, F.I., Cozano, M.A., Gangas, R.A., \& Naulin, P.I. (2014). Zonas ribereñas: protección, restauración y contexto legal en Chile. Bosque (Valdivia), 35(1), 3-12. https://dx.doi.org/10.4067/S0717-92002014000100001

Saaty, T. (2008). Decision making with the analytic hierarchy process. International Journal of Services Sciences, 1(1), 83-98.

Sabogal, C. (2008). Manejo forestal comunitario en América Latina. Experiencias, lecciones aprendidas $y$ retos para el futuro. Bogor, Indonesia: Centro para la Investigación Forestal (CIFOR).

Salvande, M., Figueroa J.A., \& Armesto, J.J. (2011). Quantity component of the effectiveness of seed dispersal by birds in the temperate rainforest of Chiloé, Chile. Bosque, 32(1), 39-45.

San Martín, C., Ramírez, C., Figueroa, H., \& Ojeda, N. (1991). Estudio sinecológico del bosque de roble-laurellingue del centro-sur de Chile. Bosque, 12(2), 11-27.

Smith-Ramírez, C., Ramos-Jiliberto, R., Valdovinos, F. S., Martínez, P., Castillo, J. A., \& Armesto, J. J. (2014). Decadal trends in the pollinator assemblage of Eucryphia cordifolia in Chilean rainforests. Oecologia, 176(1), 157-169. https://doi.org/10.1007/s00442-014-3000-0

Sutherland, W.J., Armstrong-Brown, S., Armsworth, P.R., Tom, B., Brickland, J., Campbell, C.D., Chamberlain, D.E., ... Watkinson, A.R. (2006). The identification of 100 ecological questions of high policy relevance in the UK. Journal of Applied Ecology, 43(4), 617-627. https://doi.org/10.1111/j.1365-2664.2006.01188.x

Tacón, A. (2004). Conceptos generales para la conservación de la biodiversidad. Valdivia: CIPMA. Recuperado de http://parquesparachile.cl/dmdocuments/manual_ conceptos_generales_de_conservacion.pdf

Taucher, E. (1999). Bioestadística. Santiago, Chile: Editorial Universitaria.

Vergara, G. \& Gayoso, J. (2004). Efecto de factores físicosociales sobre la degradación del bosque nativo. Bosque (Valdivia), 25(1), 43-52. https://dx.doi.org/10.4067/ S0717-92002004000100004 
WWF [Fondo Mundial para la Naturaleza]. (2004). $A$ biodiversity vision for the Valdivian temperate rain forest ecoregion of Chile and Argentina. Recuperado de https:/www.worldwildlife.org/ecoregions/nt0404

Zamorano-Elgueta C. (2014). Definición de áreas prioritarias para la restauración forestal en la Cordillera de la Costa de la Región de Los Ríos, Chile (Tesis de Doctorado, Universidad de Alcalá). Recuperada de https:/ebuah.uah.es/dspace/handle/10017/22516

\section{Agradecimientos}

Agradecimientos al Fondo de Investigación del Bosque Nativo de CONAF 027/2015 "Monitoreo de la degradación de bosques nativos desde el espacio: implementación de una estrategia territorial para su recuperación" por apoyar económicamente esta investigación. 